\title{
An analysis of clinical process measures for acute healthcare delivery in Appalachia: The Roane Medical Center experience Karla Rae Pope ${ }^{1}$, John S Hancock ${ }^{2}$ and Eric Scott Sills*3,4
}

\author{
Address: ${ }^{1}$ Department of Obstetrics and Gynecology, St. Matthew's University College of Medicine, Grand Cayman, British West Indies, ${ }^{2}$ Division \\ of Public Health Partnerships, Centers for Disease Control and Prevention, Atlanta, Georgia, USA, ${ }^{3}$ Department of Obstetrics, Gynecology and \\ Reproductive Research, Murphy Medical Center, Murphy, North Carolina, USA and ${ }^{4}$ Suite D, 75 Medical Park Drive, Murphy Medical Center, \\ Murphy, 28906, North Carolina ,USA \\ Email: Karla Rae Pope - karlapope50@hotmail.com; John S Hancock - jyh6@cdc.gov; Eric Scott Sills* - drsills@murphywomenscenter.com \\ * Corresponding author \\ Published: 29 March 2006 \\ Health Research Policy and Systems2006, 4:3 doi:10.1 I86/1478-4505-4-3 \\ Received: 15 December 2005 \\ Accepted: 29 March 2006 \\ This article is available from: http://www.health-policy-systems.com/content/4/I/3 \\ (c) 2006Pope et al; licensee BioMed Central Ltd. \\ This is an Open Access article distributed under the terms of the Creative Commons Attribution License (http://creativecommons.org/licenses/by/2.0), \\ which permits unrestricted use, distribution, and reproduction in any medium, provided the original work is properly cited.
}

\begin{abstract}
Objective: To survey management of selected emergency healthcare needs in a Tennessee community hospital.

Materials and methods: In this descriptive report, discharges and associated standard process measures were retrospectively studied for Roane Medical Center (RMC) in Harriman, Tennessee (pop. 6,757). Hospital data were extracted from a nationwide database of short-term acute care hospitals to measure 16 quality performance measures in myocardial infarction (MI), heart failure, and pneumonia during the 14 month interval ending March 2005. The data also permitted comparisons with state and national reference groups.

Results: Of RMC patients with myocardial infarction (MI), $94 \%$ received aspirin on arrival, a figure higher than both state $(85 \%)$ and national $(91 \%)$ averages. Assessment of left ventricular dysfunction among heart failure patients was also higher at RMC $(98 \%)$ than the state $(74 \%)$ or national $(79 \%)$ average. For RMC pneumonia patients, $79 \%$ received antibiotics within $4 \mathrm{~h}$ of admission, which compared favorably with State $(76 \%)$ and national $(75 \%)$ average. RMC scored higher on 13 of 16 clinical process measures $(p<0.0$ I, sign test analysis, $>95 \% \mathrm{Cl})$ compared to state and national averages.

Discussion: Although acute health care needs are often met with limited resources in medically underserved regions, RMC performed above state and national average for most process measures assessed in this review. Our data were derived from one facility and the associated findings may not be applicable in other healthcare settings. Further studies are planned to track other parameters and specific clinical outcomes at RMC, as well as to identify specific institutional policies that facilitate attainment of target quality measures.
\end{abstract}

\section{Introduction}

While health care quality in the U.S. has been found to be inconsistent and sometimes inadequate by several investigators $[1,2]$, objective assessments of quality can provide useful information as quality improvement programs are developed and implemented [3]. Some researchers have observed that care for some seriously ill patients has shown surprising and unacceptable interstudy variation 
even when objective improvements were registered at the end of an assessment period [4-6]. As a medically underserved area, Appalachia encounters any economic downturn with special vulnerability. Hospital policymakers in this region are expected to maintain delivery of health services to their communities with resources that are often limited and insufficient. Against this background, this study examined one Appalachian hospital to determine its current performance vis-à-vis selected clinical process measurements and compared these data to comparable measurements across the state and nation.

\section{Materials and methods Study hospital}

Roane Medical Center (RMC) is a 109-bed primary care hospital owned and operated by the city of Harriman, Tennessee (population 6,757). The hospital was established as Harriman City Hospital in 1939 initially opening with 50 beds. With closure of other small area hospitals over the next decades, this facility became the county's only hospital and was reincorporated as Roane Medical Center in 1996. The hospital's emergency department registered 23,879 patient encounters in 2004. For 2004, RMC's total annual operating budget was $\$ 36 \mathrm{M}$. RMC serves Roane and neighboring counties, most of which (like Roane County) have been designated medically underserved areas [7].

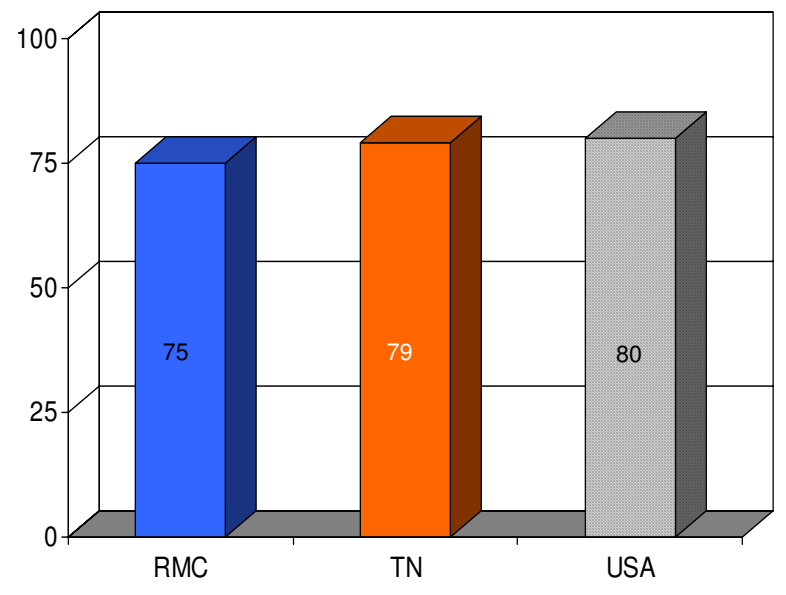

Figure I

Proportion of patients with myocardial infarction $(n=8)$ given angiotensin converting enzyme inhibitor therapy for left ventricular dysfunction within $24 \mathrm{~h}$ of hospital admission (\%) at Roane Medical Center (RMC). Mean percentages of patients receiving this treatment in Tennessee (TN) and all hospitals (USA) are also shown for comparison.

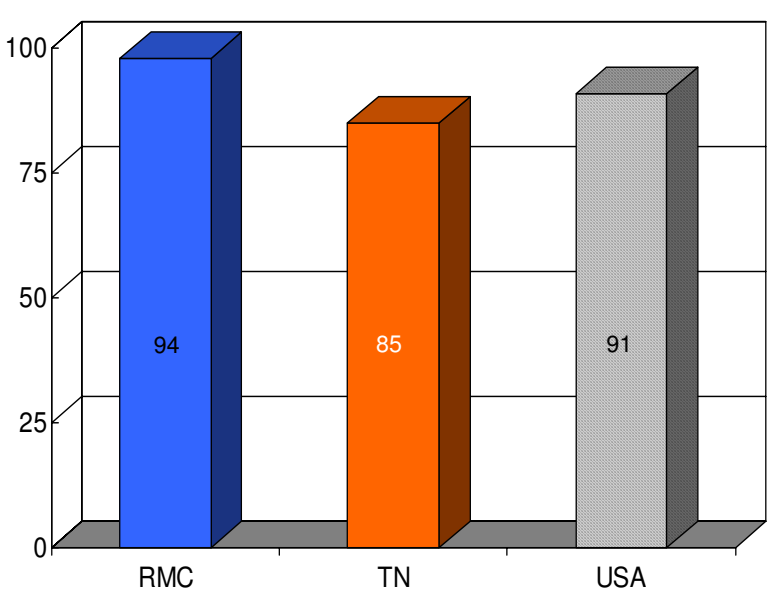

Figure 2

Proportion of myocardial infarction patients $(n=47)$ given aspirin upon arrival at Roane Medical Center (RMC). Mean percentages of patients receiving this treatment in Tennessee (TN) and all hospitals (USA) are also shown for comparison.

\section{Data source and statistical analysis}

This descriptive study was based on national data collected by short-term acute care hospitals and rural, small, remote "critical access" hospitals and reported to the Centers for Medicare and Medicaid Services. RMC was among the reporting hospitals $(n=3558)$ that voluntarily submitted data in order to receive an incentive payment established by Section 501(b) of the Medicare Prescrip-

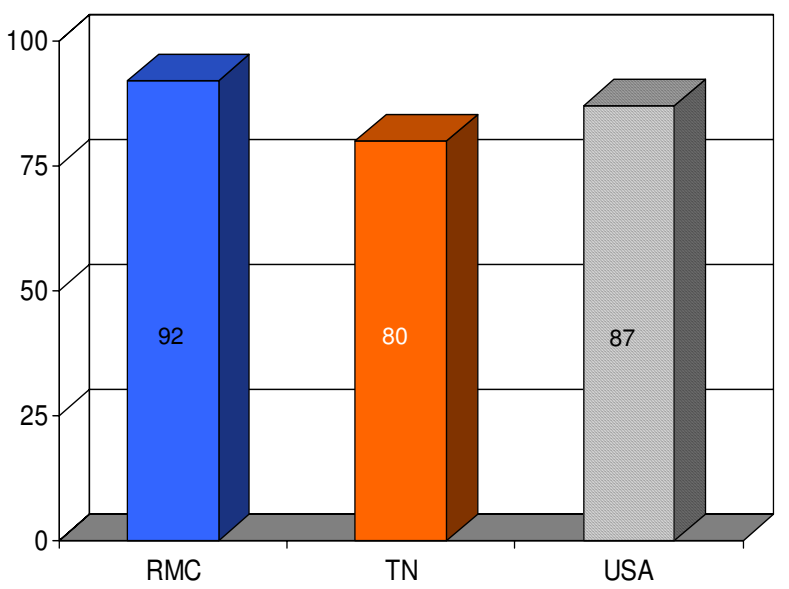

Figure 3

Proportion of myocardial infarction patients $(n=25)$ given aspirin at discharge from Roane Medical Center (RMC). Mean percentages of patients receiving this intervention in Tennessee (TN) and all hospitals (USA) are also shown for comparison. 


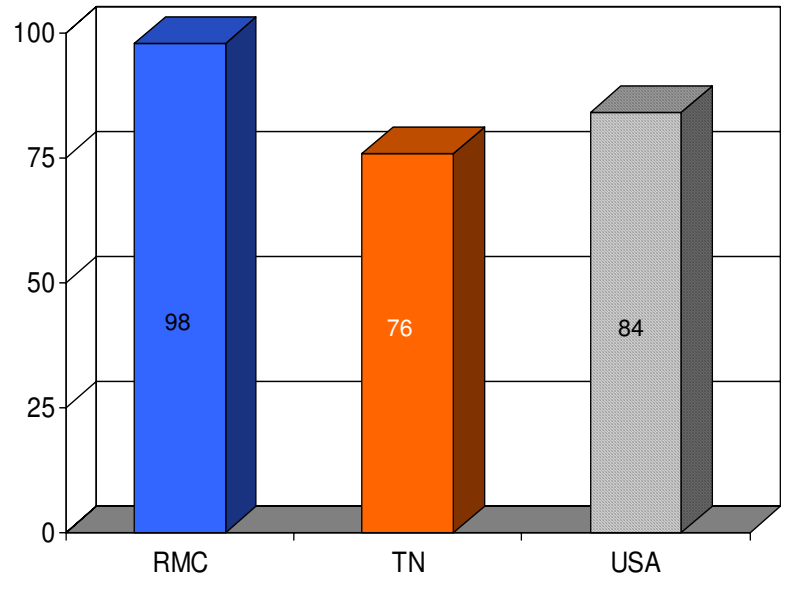

Figure 4

Proportion of myocardial infarction patients $(n=42)$ given beta-blocker upon arrival at Roane Medical Center (RMC). Mean percentages of patients receiving this intervention in Tennessee (TN) and all hospitals (USA) are also shown for comparison.

tion Drug, Improvement and Modernization Act of 2003 (MMA). To qualify for such funds, MMA required eligible hospitals to report on an initial set of ten quality performance measures targeting patients diagnosed with acute myocardial infarction (MI), heart failure, and pneumonia and agree to make the data public. Subsequently, most hospitals agreed to participate in the Hospital Quality

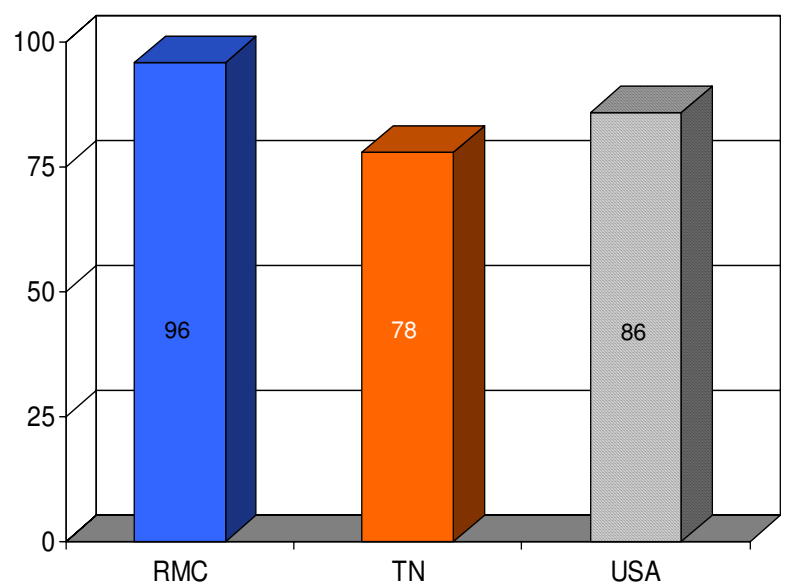

\section{Figure 5}

Proportion of myocardial infarction patients $(n=25)$ given beta-blocker at discharge from Roane Medical Center (RMC). Mean percentages of patients receiving this intervention in Tennessee (TN) and all hospitals (USA) are also shown for comparison.

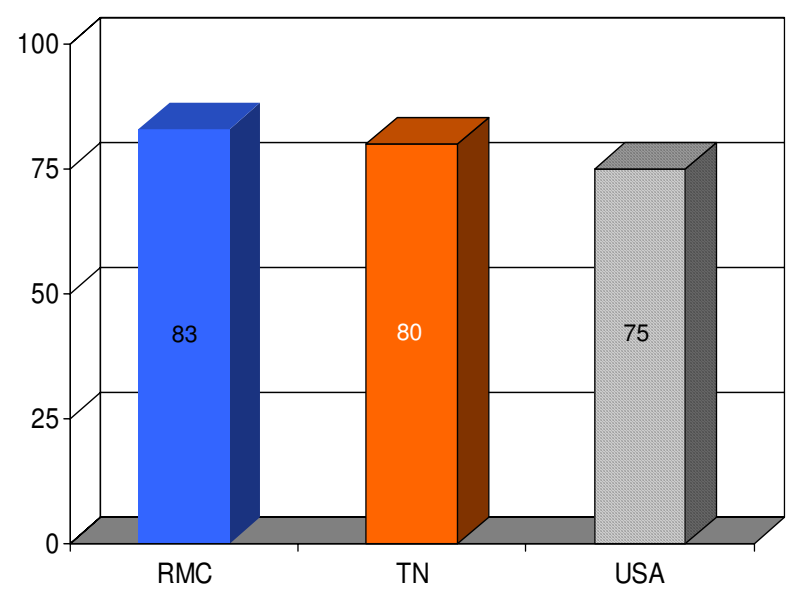

Figure 6

Proportion of myocardial infarction patients $(n=6)$ given smoking cessation counseling/advice before discharge from Roane Medical Center (RMC). Mean percentages of patients receiving this intervention in Tennessee (TN) and all hospitals (USA) are also shown for comparison.

Alliance (HQA) - the first nationwide initiative to report on hospital performance. Beginning with the second quarter 2004 (April-June), hospitals participating in HQA could elect to submit data on an additional seven indicators of quality of care for these three diagnostic categories. Data were available for most clinical process measures for

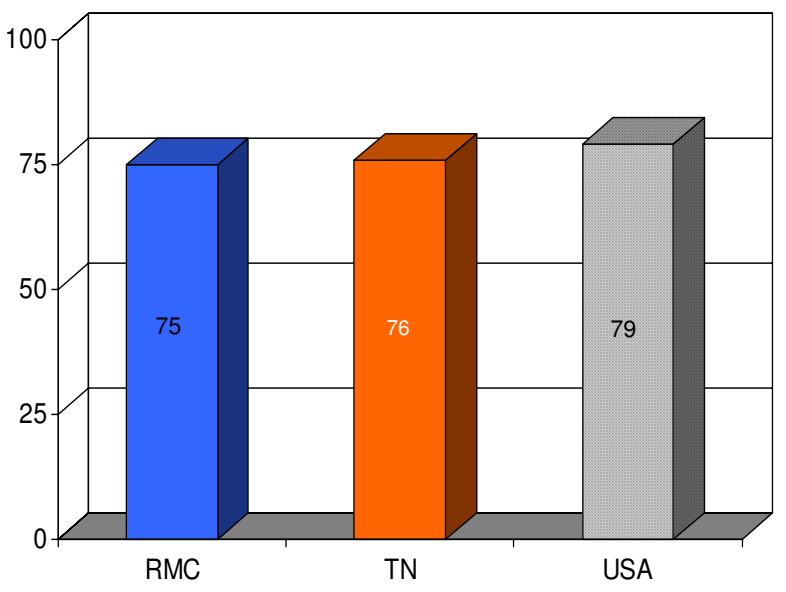

Figure 7

Proportion of patients with left ventricular dysfunction $(n=$ 16) given an angiotensin converting enzyme inhibitor within $24 \mathrm{~h}$ of admission at Roane Medical Center (RMC). Mean percentages of patients receiving this intervention in Tennessee (TN) and all hospitals (USA) are also shown for comparison. 


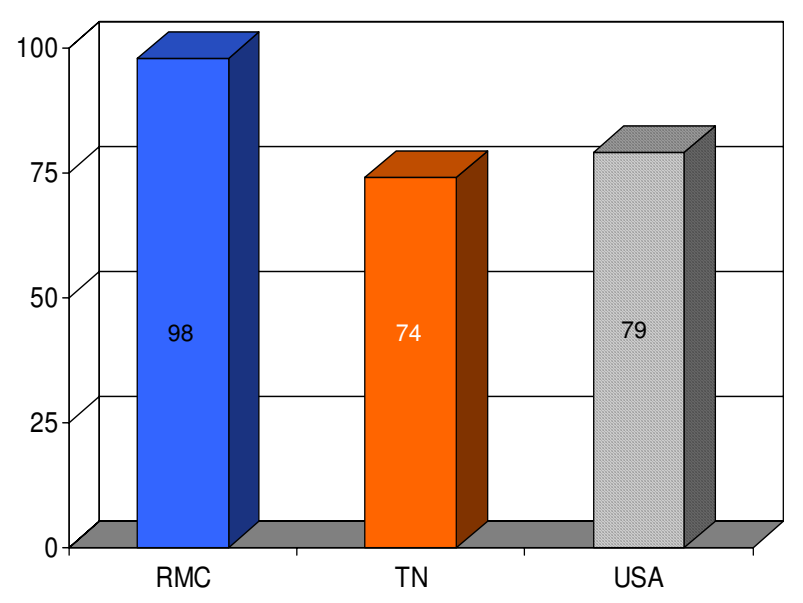

Figure 8

Proportion of heart failure patients $(n=148)$ receiving left ventricular function assessment at Roane Medical Center (RMC). Mean percentages of patients receiving this intervention in Tennessee (TN) and all hospitals (USA) are also shown for comparison.

a 14 month period ending March 2005, although 2 of the parameters included in this study had a narrower measurement interval (January-March 2005).

The HQA data set provides a large quantity of information about U.S. hospitals where data on at least one stable measure (defined as discharge information derived from

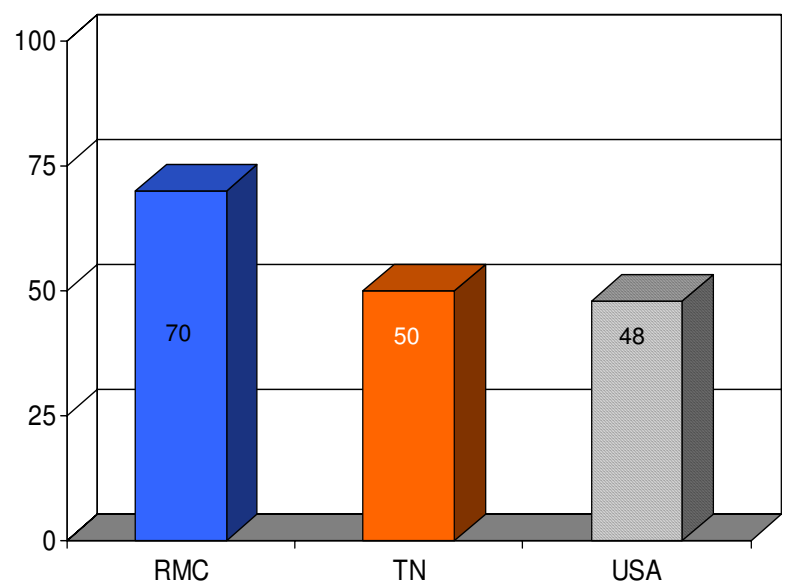

\section{Figure 9}

Proportion of heart failure patients $(n=102)$ receiving instructions at discharge from Roane Medical Center (RMC). Mean percentages of patients receiving discharge instructions in Tennessee (TN) and all hospitals (USA) are also shown for comparison.

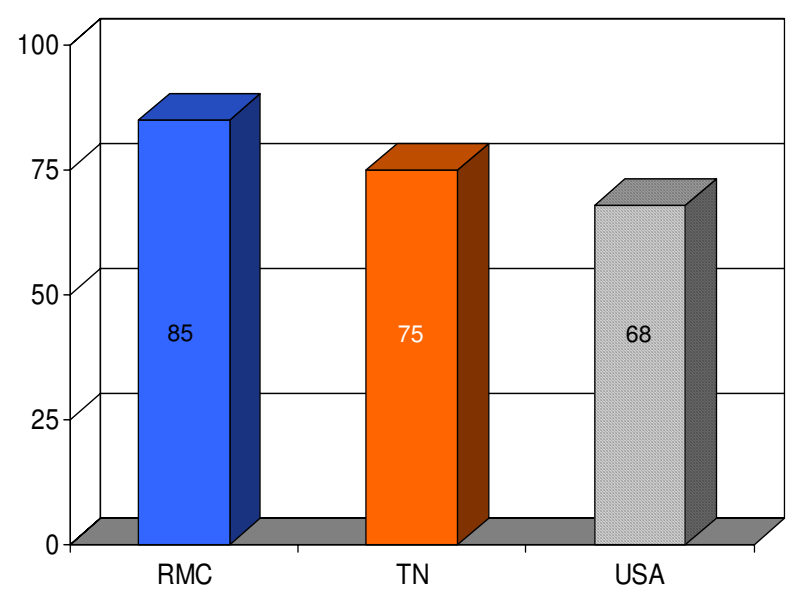

Figure 10

Proportion of patients with left ventricular systolic dysfunction $(n=26)$ given smoking cessation counseling/advice at Roane Medical Center (RMC). Mean percentages of patients receiving this intervention in Tennessee (TN) and all hospitals (USA) are also shown for comparison.

at least 25 patients) was reported during the study period. Our retrospective analysis was based on information extracted from this database specific to RMC, derived from administrative data and medical record documents as primary sources maintained at that facility. RMC's performance data were then referenced with state (Tennessee) and

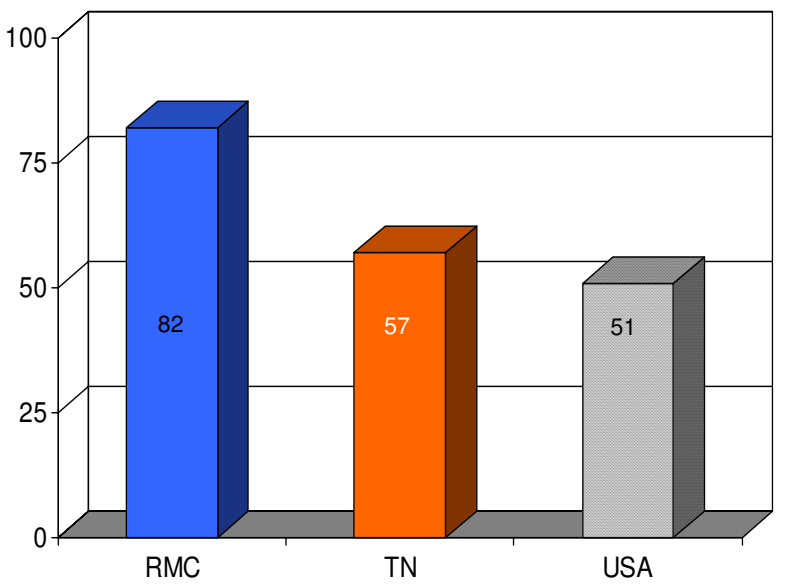

Figure II

Proportion of pneumonia patients $(n=195)$ receiving pneumococcal vaccination before discharge from Roane Medical Center (RMC). Mean percentages of patients receiving this intervention in Tennessee (TN) and all hospitals (USA) are also shown for comparison. 


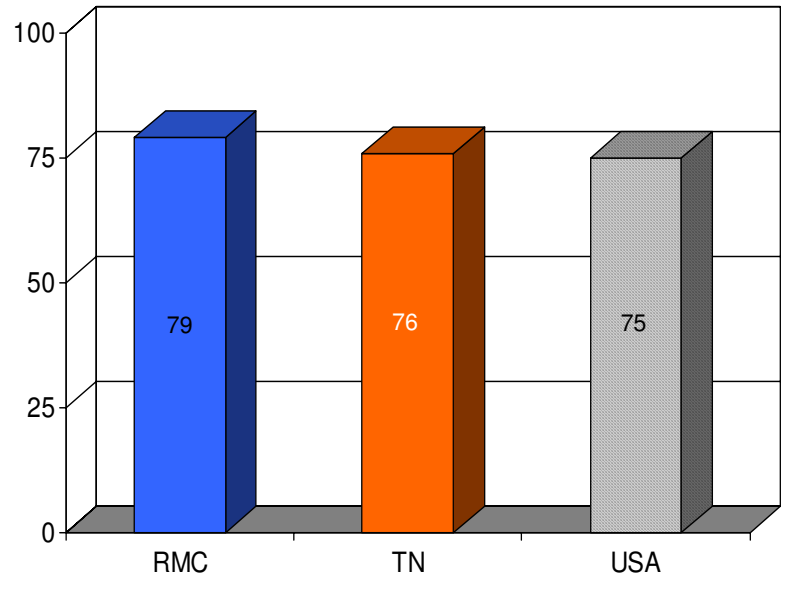

Figure 12

Proportion of pneumonia patients $(n=269)$ receiving intravenous antibiotics within $4 \mathrm{~h}$ of admission at Roane Medical Center (RMC). Mean percentages of patients receiving this treatment in Tennessee (TN) and all hospitals (USA) are also shown for comparison.

U.S. national average data for comparison using sign test methodology [8].

\section{Results}

We found RMC's score on a majority (13/16) of clinical parameters to be above state and U.S. national reference groups. Specifically, the study hospital's performance on

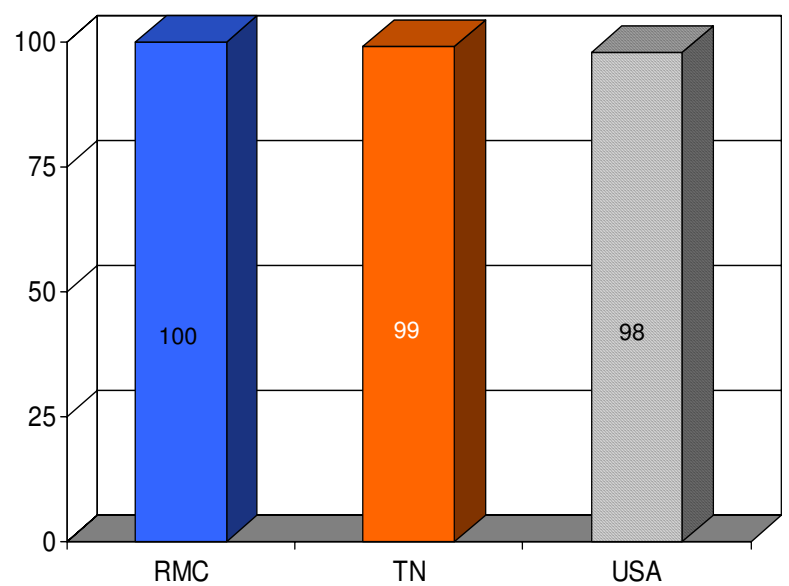

Figure 13

Proportion of pneumonia patients $(n=316)$ undergoing oxygenation assessment within $24 \mathrm{~h}$ of admission at Roane Medical Center (RMC). Mean percentages of patients having this test in Tennessee (TN) and all hospitals (USA) are also shown for comparison.

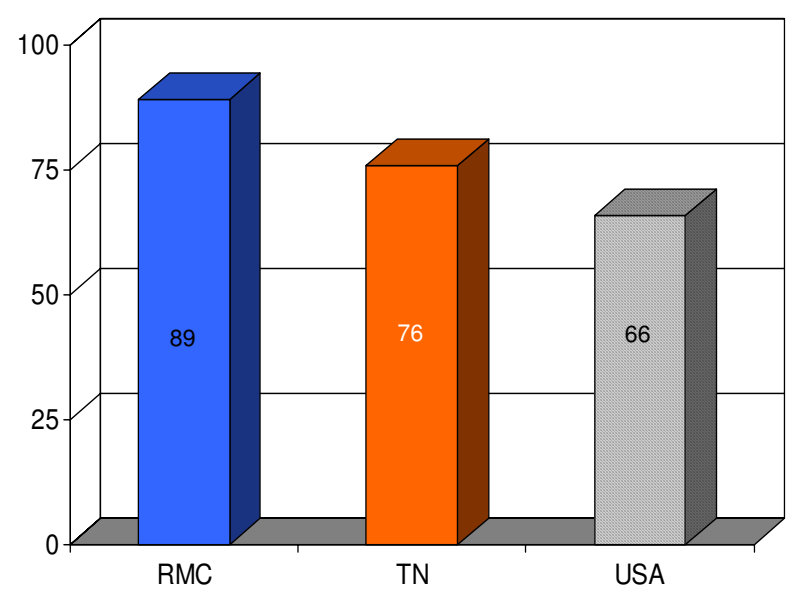

Figure 14

Proportion of pneumonia patients $(n=108)$ receiving smoking cessation counseling/advice from Roane Medical Center (RMC). Mean percentages of patients receiving this intervention in Tennessee (TN) and all hospitals (USA) are also shown for comparison.

utilization of aspirin on arrival and discharge for myocardial infarction was higher than the state and national average. Administration of beta-blockers for myocardial infarction at RMC was also greater compared to both Tennessee and USA average. Heart failure patients underwent assessment of left ventricular function more often at RMC compared to the state and national average, and RMC

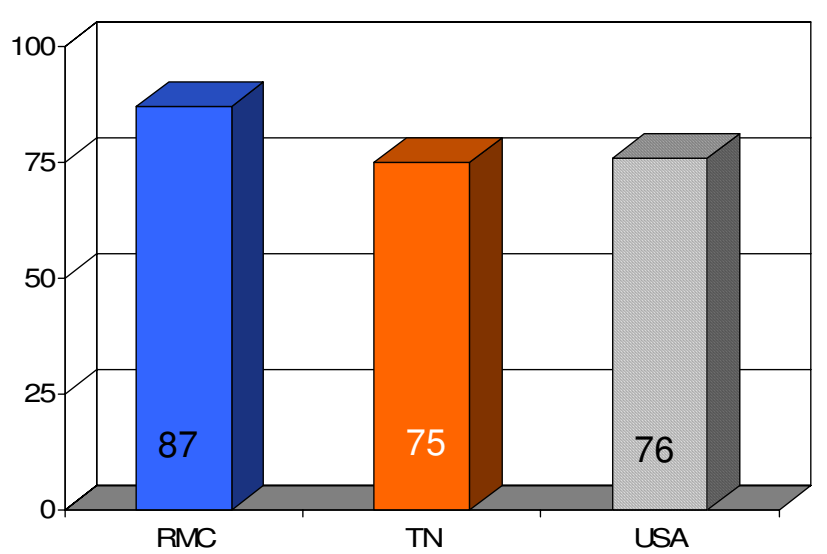

Figure I 5

Proportion of pneumonia patients $(n=197)$ receiving most appropriate intravenous antibiotics at Roane Medical Center (RMC). Mean percentages of patients receiving this treatment in Tennessee (TN) and all hospitals (USA) are also shown for comparison. 


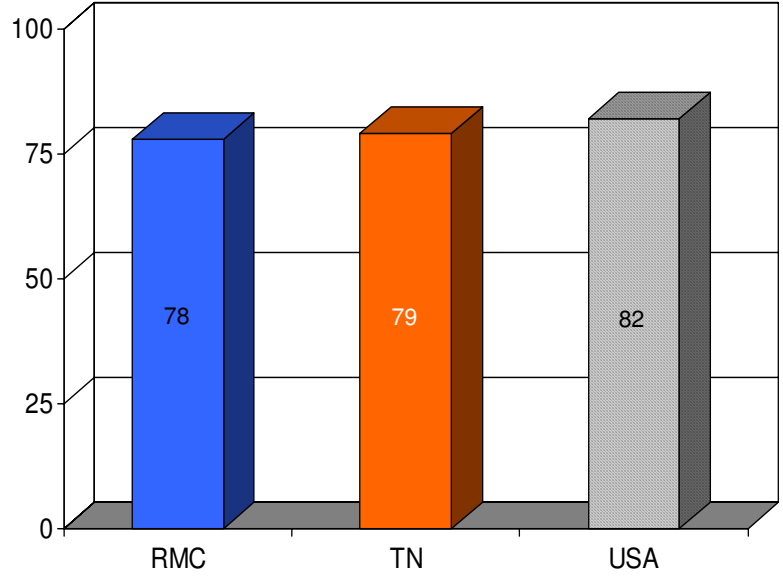

\section{Figure 16}

Proportion of pneumonia patients $(n=285)$ having blood cultures obtained before administration of intravenous antibiotics at Roane Medical Center (RMC). Mean percentages of patients undergoing this intervention in Tennessee (TN) and all hospitals (USA) are also shown for comparison.

pneumonia patients were treated with intravenous antibiotics at a higher rate than state and national averages. An exception to this trend was noted in RMC's performance on angiotensin converting enzyme inhibitor use among heart attack patients. On this process measure only $78 \%$ of patients received the intervention compared to $79 \%$ and $80 \%$, as state and national average, respectively. For uncertain reasons, the proportion of heart failure patients receiving angiotensin converting enzyme inhibitor was also nominally below standard reference groups (75\% vs $76 \%$ and $79 \%$, state and national average, respectively). Center-specific data for RMC cardiac patients given thrombolytic medication within $30 \mathrm{~min}$ of arrival or those receiving percutaneous coronary interventions within $120 \mathrm{~min}$ of arrival could not be compared to reference groups, because these services were not provided at the study hospital. RMC's performance as measured by the HQA initiative for all relevant categories is compared to state and national reference groups in figures $1,2,3,4$, $5,6,7,8,9,10,11,12,13,14,15,16$ and Table 1.

\section{Discussion}

Appalachia is one of several U.S. regions often identified as medically underserved [9], and its formidable healthcare needs have been described by numerous investigators $[10,11]$. Against this background, hospitals have confronted the challenge of diminished reimbursement, high expenses, limited staffing and other financial hardships in a variety of ways. An uncertain and difficult economic climate in the region has contributed to closure or consolidation of many small hospitals providing important primary care services to their local communities $[12,13]$.

Table I: Quality measure comparisons for Roane Medical Center, Tennessee state average, and USA national average for selected clinical parameters as assessed by the Hospital Quality Alliance

\begin{tabular}{|c|c|c|c|c|}
\hline Parameter & RMC (n) & State & USA & Comparison \\
\hline ACE inhibitor for $\mathrm{Ml}^{\mathrm{a}}$ & $75(8)$ & 79 & 80 & - \\
\hline ASA for MI (on arrival) & $94(47)$ & 85 & 91 & + \\
\hline ASA for MI (at discharge) & $92(25)$ & 80 & 87 & + \\
\hline$\beta$-blocker for MI (on arrival) & $98(42)$ & 76 & 84 & + \\
\hline$\beta$-blocker for MI (at discharge) & $96(25)$ & 78 & 86 & + \\
\hline Smoking cessation for MI & $83(6)$ & 80 & 75 & + \\
\hline ACE for $H F a$ & $75(16)$ & 76 & 79 & - \\
\hline Assessment of LV function for $\mathrm{HF}$ & $98(148)$ & 74 & 79 & + \\
\hline Discharge instructions for HF & $70(102)$ & 50 & 48 & + \\
\hline Smoking cessation for HF & $85(26)$ & 75 & 68 & + \\
\hline Vaccination for pneumonia & $82(195)$ & 57 & 51 & + \\
\hline $\mathrm{ABX}$ within $4 \mathrm{~h}$ for pneumonia & $79(269)$ & 76 & 75 & + \\
\hline $\mathrm{O}_{2}$ assessment in pneumonia & $100(316)$ & 99 & 98 & + \\
\hline Smoking cessation for pneumonia & $89(108)$ & 76 & 66 & + \\
\hline Most appropriate $A B X$ for pneumoniab & $87(197)$ & 75 & 76 & + \\
\hline \multirow[t]{2}{*}{ Blood cultures for pneumonia } & $78(285)$ & 79 & 82 & - \\
\hline & \multicolumn{4}{|c|}{$p<0.01 c$} \\
\hline
\end{tabular}

Notes: All data presented as percentages (n), and were collected from July 2004-March 2005, except as noted. $n=$ total patients in criteria set (denominator) $\mathrm{ACE}=$ angiotensin converting enzyme inhibitor $\mathrm{MI}=$ myocardial infarction $\mathrm{ASA}=$ aspirin $\mathrm{PCl}=\mathrm{percutaneous}$ coronary intervention $\mathrm{HF}=$ heart failure $\mathrm{ABX}=$ antibiotics

a Data for this process measure were available for the January 2005-March 2005 interval only

b Data for this process measure were available for the July 2004-March 2005 interval only

c by sign test 
Several healthcare institutions in Appalachia have adapted to the changing healthcare landscape, even managing to register growth despite a hostile marketplace. One facility that has weathered this storm is Roane Medical Center (RMC), located in Harriman, Tennessee. A study of specific management strategies potentiating the survival and growth of this institution is beyond the scope of the current report. Instead, we focused on objective measurement of RMC's performance with a select group of standardized acute healthcare clinical processes as measured by the Hospital Quality Alliance (HQA). This initiative is the first effort to report data on hospital performance on a national scale [14], and permitted comparison of RMC with reference groups both within Tennessee as well as nationwide.

Research based on HQA data recently found no relationship between clinical performance on these standardized parameters and hospital size [14]. However, these investigators found a small but significant increase in performance among academic, Northeastern or Midwestern nonprofit hospitals. Southern and far Western states, in contrast, tended to do less well on heart care measures [15]. Our research found RMC (a small, non-academic, not-forprofit hospital in the rural South) performed above state and national average on most of these specific clinical parameters. Indeed, the only process measures where RMC performed marginally under state and national average was among pneumonia patients receiving blood cultures, and heart failure/myocardial infarction patients receiving angiotensin converting enzyme inhibitor therapy.

Our analysis was limited by several factors. The clinical parameters covered in this report did not capture data on all hospital encounters, and represent only about $15 \%$ of all Medicare admissions [14]. It must be acknowledged that process measures are distinct from patient outcomes, and this investigation assessed only the former. Since $\mathrm{RMC}$ is a small facility, the number of patients presenting with certain medical conditions during the study interval was limited and likely introduced some error due to insufficient sampling. Our results describe process measures only at one institution and may not apply to different health care facilities where different policies and practices prevail. We also assumed the data reported represented independent variables, permitting robust comparisons for each process measurement. Additionally, while data collecting and public reporting of healthcare quality measures to the HQA database is an important beginning, our findings suggest that other relevant clinical benchmarks will need to be surveyed going forward. Data gathering should be expanded to include more diseases and conditions to depict a more complete picture of hospital care in rural Appalachia and nationwide. The HQA project presents valuable information for consumers, physicians, and administrators - all of whom have an interest in improving hospital care in the U.S.

\section{Competing interests}

The author(s) declare that they have no competing interests.

\section{Authors' contributions}

KRP, JSH and ESS contributed equally to this manuscript.

\section{References}

I. Jencks SF, Huff ED, Cuerdon T: Change in the quality of care delivered to Medicare beneficiaries, 1998-1999 to 2000200I. JAMA 2003, 289:305-I2.

2. McGlynn EA, Asch SM, Adams J, Keesey J, Hicks J, DeCristofaro A, Kerr EA: The quality of health care delivered to adults in the United States. N Engl J Med 2003, 348:2635-45.

3. Galvin R, Milstein A: Large employer's new strategies in health care. N Engl J Med 2002, 347:939-42.

4. Krumholz HM, Baker DW, Ashton CM, Dunbar SB, Freisinger GC, Havranek EP, Hlatky MA, Konstam M, Ordin DL, Pina B, Pitt B, Spertus JA: Evaluating quality of care for patient with heart failure. Circulation 2000, I0I:EI22-EI40.

5. Burwen DR, Galusha DH, Lewis JM, Bedinger MR, Radford MJ, Krumholz HM, Foody JM: National and state trends in quality of care for acute myocardial infarction between 1994-1995 and 1998-1999: the medicare health care quality improvement program. Arch Intern Med 2003, 163:1430-1439.

6. Spertus JA, Radford MJ, Every NR, Ellerbeck EF, Peterson ED, Krumholz HM: Acute myocardial infarction working group of the American Heart Association/American College of Cardiology First Scientific Forum on Quality of Care and Outcomes Research in Cardiovascular Disease and Stroke. J Am Coll Cardiol 2003, 41:1653-1663.

7. Health professional shortage area list (Tennessee). In U.S. Department of Health and Human Services U.S. Government Printing Office, Washington DC; 2004.

8. Rayner JC, Best DJ: Modelling ties in the sign test. Biometrics 1999, 55:663-5.

9. Finerman R, Blanchard-Horan C, Jowers S, Brittman S: The dual enrolled as a disadvantaged population: developing culturally informed interventions for Tennessee Medicare/Medicaid women. J Health Hum Serv Adm 2003, 26:269-97.

10. Moscovice I, Stensland J: Rural hospitals: trends, challenges, and a future research and policy analysis agenda. I Rural Health 2002, 18(Suppl): | 97-210.

II. Shively EH, Shively SA: Threats to rural surgery. Am J Surg 2005, 190:200-5.

12. Ludke RL, Westhoff LJ, Flood BM: Rural hospitals' viability and strategic responses. Health Prog 1992, 73:49-53.

13. Wells R, Lee SY, McClure J, Baronner L, Davis L: Strategy development in small hospitals: stakeholder management in constrained circumstances. Health Care Manage Rev 2004, 29:2 I 8-28.

14. Jha AK, Li Z, Orav EJ, Epstein AM: Care in U.S. hospitals - the Hospital Quality Alliance program. N Engl J Med 2005, 353:265-74

15. Fessenden F: It's the simple things, but some hospitals don't do them. The New York Times :21. August 21, 2005 